\title{
21
}

\section{Allocating RDII Using Footing Drain Flow and Other Information}

\author{
Benjamin J. Sherman, Pete P. Perala, Marc C. Stonehouse, \\ Henry P. Fan, and Mark J. TenBroek
}

Rainfall dependent inflow and infiltration (RDII) can be modeled in different ways using the United States Environmental Protection Agency Stormwater Management Model (SWMM). This includes using the RDII shape and volume routines in the SWMM RUNOFF module; using typical combined area parameters for a reduced sub-basin area to produce an inflow response; and using baseflow factors in EXTRAN or the groundwater routine in RUNOFF to produce an infiltration response. Regardless of methods used to model RDII, quantifying RDII can be performed by an even wider variety of methods, typically tailored to local conditions as no one method is universally applicable (Shultz et al.).

For this chapter, the RDII shape and volume routines in RUNOFF are used. Total wet weather response is allocated based on understanding of connected footing drains tributary to the sanitary collection system and supporting sewer metering and footing drain flow monitoring data. Footing drain contribution to RDII is important to the local conditions of the Ann Arbor sanitary collection system (Sanitary Sewer Overflow Study Task Force; Sherman et al.; Stonehouse et al.; Zawacki et al.). In Ann Arbor, an extensive Footing Drain Disconnection (FDD) program is currently underway. The citywide model's hydrology required characterization that could be used to prioritize FDD work as well as allow ready updates to the model hydrology as work proceeds.

Sherman, B.J., P.P. Perala, M.C. Stonehouse, H. Fan and M.J. TenBroek. 2006. "Allocating RDII Using Footing Drain Flow and Other Information." Journal of Water Management Modeling R225-21. doi: 10.14796/JWMM.R225-21.

(C) CHI 2006 www.chijournal.org ISSN: 2292-6062 (Formerly in Intelligent Modeling of Urban Water Systems. ISBN: 0-9736716-2-9) 
This chapter provides some background regarding the footing drain monitoring information. This information discusses seasonal variation in response volume while exhibiting little seasonal differences for peak flow; thus, indicating that inflow responses are fairly consistent through the year and the infiltration response is what predominantly undergoes seasonal change. Also, discussed is a site characterization index (SCI) that may be used to assess likelihood of a range of footing drain responses based on a simple site assessment. Applicability of this index to other areas of the city is planned for future investigation.

\subsection{Conceptual Hydrologic Model and Incorporation of Footing Drain Flows}

The general hydrologic model centers on the use of the RDII parameters $\mathrm{R}$, $\mathrm{T}$, and $\mathrm{K}$ for up to three component hydrographs. For this work, two component hydrographs were considered; one defining the more direct response, or inflow, and the other defining the delayed response, or infiltration.

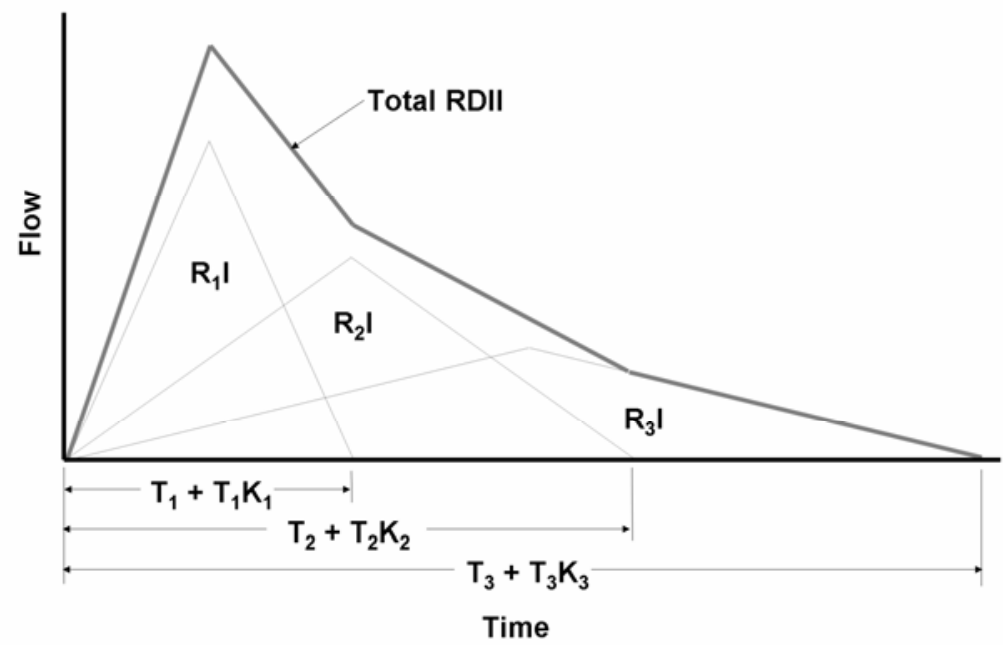

Figure 21.1 Component hydrograph parameters. 
Figure 21.1 illustrates the component hydrographs and $\mathrm{R}, \mathrm{T}$ and $\mathrm{K}$ for the three components allowed by SWMM. Note this chapter makes use of the first and third component hydrographs only as the second hydrograph was not required to adequately define the responses observed.

To provide model resolution with the ability to make updates and run simulations in conjunction with the ongoing FDD program, 2,670 sub-basins were delineated to provide hydrologic input to an approximately 11,000 node hydraulic model. The tributary area is approximately $34.2 \mathrm{mi}^{2}$ $\left(88 \mathrm{~km}^{2}\right)$. System response information from 40 flow meters was allocated to each of the 2,670 sub-basins. To do this, each sub-basin is assigned to an incremental RDII analysis area. Instead of assigning constant response values to sub-basins within a given incremental RDII analysis area, GIS information was used to better allocate response information based on subbasin characteristics.

Both dry and wet weather response parameters were allocated differently depending on whether or not each sub-basin has connected footing drains present. Therefore, a key part of this allocation was to determine the number of equivalent footing drains in each sub-basin. A footing drain equivalent includes all single-family residential properties constructed between 1945 and 1981 inclusively and all multi-family properties constructed prior to 1982. The single-family residential properties built between 1945 and 1981 each count as one FD equivalent. The FD equivalent of pre-1982 multifamily units is calculated as the building footprint-area divided by $1,200 \mathrm{ft}^{2}$ $\left(111.5 \mathrm{~m}^{2}\right)$; the average single-family residential basement area based on other work for the city of Ann Arbor). The 1945 cutoff was based on wet weather responses plotted against percentages of homes with footing drains grouped by year-built ranges. Note: Following the modeling, additional field inspection was performed, in part, to assess when use of footing drains first became an accepted practice in the Ann Arbor area. These inspections indicate the 1945 cutoff should be revised to 1935. The 1982 cutoff is determined as the point in which local building codes began enforcement of construction practices that prevented connection of footing drains to the sanitary collection system. The allocation method provides a mechanism for updating the system response parameters as the FDD work continues and footing drains are removed from the system. Commercial/industrial structure contributions from footing drains were determined to be negligible based on a related study and were not included in the allocation. However, that was limited to a small study area and it is possible that some commercial/industrial structures do contribute significant footing drain flows or roof drain flows in other areas of the city. 
RDII event volumes were categorized into one of two seasons: Dormant (winter, spring, and fall) and Growth (summer). During the Growth season, which typically extends from mid-May to mid-September in the Ann Arbor area, groundwater levels and soil moisture levels are reduced through evapotranspiration. This correspondingly reduces the RDII response from storms into the sanitary system. RDII volumes for each season's set of data were plotted against the total rainfall volumes. Based on analysis of the 2003 data collected during this project, a very distinct time was identified for this transition, as shown in Figure 21.2 by the change in RDII volume versus the amount of rainfall.

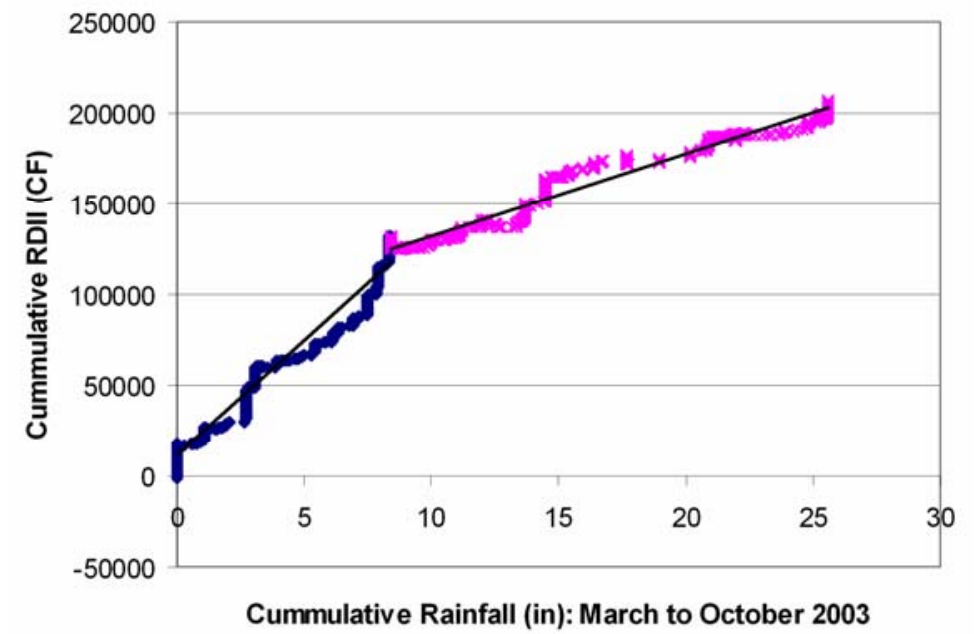

Figure 21.2 Seasonal breakpoint.

For each season, a best-fit regression to the data was prepared to establish an average capture coefficient by season for each meter tributary area. These plots were used to set the calibration, validation, and design parameters for the model. An example of these plots is given in Figure 21.3. 


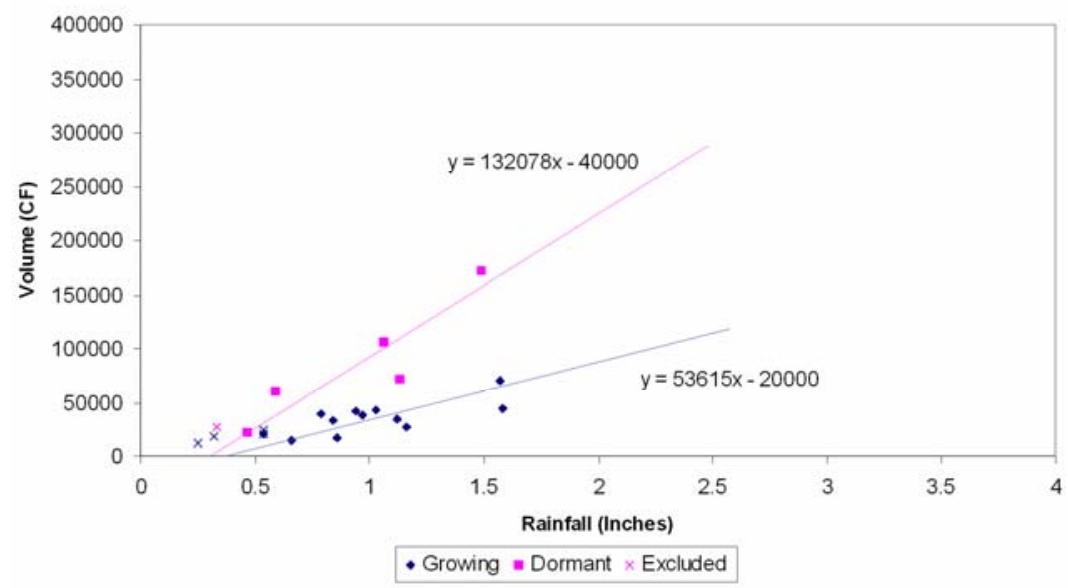

Figure 21.3 Seasonal response to rainfall relationships.

\subsection{Footing Drain Information}

Through the FDD program, 28 sump pump monitors have been installed in houses, having undergone disconnection through the end of 2003. This monitoring has increased in number of locations and will continue at least through the end of 2005. These devices monitor pump ON and OFF events that are converted to FD flows based on average pumping rates determined by drawdown tests. The resulting flow data provide an estimate of the effectiveness of the program. Some of the monitors remain in a fixed location to serve as a baseline reference; whereas, the remaining monitors are periodically moved to other newly completed disconnection locations to record data from a broader sample set.

During the period of analysis, 19 storm events were identified that were greater than 1 in $(25.4 \mathrm{~mm})$. Wet weather responses were identified for each monitor during each of the 19 events for which the monitor was recording data e.g. most monitors were not installed for the full $2 \mathrm{y}$ period and consequently had fewer than the 19 event responses to analyze.

In addition to flow and precipitation data, the following qualitative site assessments were made for each monitoring location:

- Percentage of downspouts discharging within $5 \mathrm{ft}(1.5 \mathrm{~m})$ of house: expressed approximately as $0,25,50,75$, or $100 \%$. 
- Grading: expressed as Good, Average, or Poor. Where Good is approximately steeper than $10 \%$ grade away from house, Average is a mild slope away from house (less than 10\%), Poor is any adverse slope toward the house even if only occurring for a small percentage of house perimeter.

- Landscaping: expressed as Good, Average, or Poor. Where Good represents extensive vegetation and mulching within $20 \mathrm{ft}$ $(6.1 \mathrm{~m})$ of house, Average represents average vegetation and mulching within $20 \mathrm{ft}(6.1 \mathrm{~m})$ of house, and Poor represents little vegetation and mulching within $20 \mathrm{ft}(6.1 \mathrm{~m})$ of house.

- Elevation relative to surroundings: expressed as Low, Medium, or High. Where High represents homes at a much greater elevation than its immediate surroundings, Medium classifies homes with fairly level surroundings or an equal ratio of surroundings at both higher and lower elevations, and Low represents homes with the majority of its immediate surroundings at a higher elevations.

A trend between site characteristics and FD responses was identified and later compared to results from a larger storm not used in the initial development. Figures 21.4 and 21.5 are the results of a preliminary assessment of using the SCI defined by Equation 21.1. Figure 21.4 shows the average response slopes for footing drains against the SCI determined using Equation 21.1. The regression line is presented for illustrative purposes and is not intended to be used as an estimator of response given the somewhat weak fit. However, Figures 21.4 and 21.5 do illustrate that the $\mathrm{SCI}$ does exhibit a trend when compared with the FD responses. The higher the SCI's for a sufficient number of properties, the greater the average response of those collective properties is likely to be.

$S C I=0.3 \cdot D S_{\text {rank }}+0.2 \cdot G D_{\text {rank }}+1.5 \cdot L S_{\text {rank }}+3.5 \cdot E L_{\text {rank }}$

where:

- $\mathrm{DS}_{\mathrm{rank}}$ - based on percentage of downspouts discharging within $5 \mathrm{ft}(1.5 \mathrm{~m})$ of house, and $=0$ for $0 \%,=1$ for $25 \%,=2$ for $50 \%$, $=3$ for $75 \%$ and $=4$ for $100 \%$.

- $\mathrm{GD}_{\text {rank }}$ - based on site grading characterization, and $=0$ for Good, = 1 for Average, and $=2$ for Poor.

- $\quad \mathrm{LS}_{\mathrm{rank}}$ - based on site landscaping characterization, and $=0$ for Good, $=1$ for Average, and $=2$ for Poor. 
- $\quad \mathrm{EL}_{\mathrm{rank}}-$ based on site elevation characterization, and $=0$ for High, $=1$ for Medium, and $=2$ for Low.

The relationship found between site conditions and footing drain response is not unexpected. However, a simple means to define this relationship was previously not established. The SCI is rudimentary and could be improved through refinement of input. The SCI is most sensitive to the elevation term suggesting the greatest potential for refinement in predicting FD flow at a given location. The relative elevation represents more complex site factors such as groundwater level relative to the footing drains, prevailing ground slope, etc. This term may be improved through a more objective evaluation that might make use of topographic contours and surface water locations. An improved relationship such as this could be used to prioritize remaining FDD work to maximize FD flow removal by investing disconnection effort and resources in the areas most likely to see the greatest reduction in FD flow.

The SCI defined by Equation 21.1 was developed by adjusting coefficients until an increasing SCI corresponded to a measurable extent with increasing FD response. Equation 21.1 development is based on storms of moderate volume and intensity. It was understood that behavior of footing drain responses may be quite different under larger more intense storms. Therefore, the SCI relationship expressed by Equation 21.1 was compared to results from a storm event that resulted in significant stress on the collection system. Figure 21.6 indicates that the trend of increasing response with increasing SCI continues to be observed in the extreme event data. The results for this extreme event are presented in Figure 21.6 only and are not part of any other analysis discussed in this chapter; this significant event occurring in March of 2004. And, as expected, the responses are greater than those previously considered. This difference suggests an inadequacy of the use of a regression relationship between SCI and response to predict average responses for the more extreme storm events. However, this difference has no affect on the result that the SCI may well be a useful indicator of properties that are more likely to yield higher FD responses.

The SCI relationship is built on monitoring properties in areas of FDD work performed through the end of 2003 and may not accurately be extended to future FDD work areas. Consequently, any effort to apply this to other areas should be predicated by some early monitoring to confirm adequacy of relationship used.

Figure 21.4 indicates a significant amount of scatter at the higher SCI values as can be observed in the regression results; Figure 21.5 simplifies the 
statistics in terms of averages for each quartile of data from lowest to highest SCI values. What is important is not the goodness of the fit of the regression line in Figure 21.4, but the realization that there is a trend that perhaps can be improved upon. Both Figures 21.4 and 21.5 indicate that a low SCI has a greater likelihood of having FDs that contribute less flow than those having a high SCI. Figure 21.6 confirms this trend exists under larger storm conditions. It is unlikely that the scatter in Figure 21.4 could be reduced dramatically through refinement of the SCI relationship given the high variability in FD responses observed.

Because the site characterization is subjective, if this method were applied on a larger scale, more rigid definitions would have to be established to minimize inconsistencies in information gathering. The SCI was developed at the conclusion of the modeling work and was not used for RDII allocation. However, it is presented in this Chapter due to its potential for use in refining the model's RDII allocation in the future or to verify the adequacy of the present allocation method.

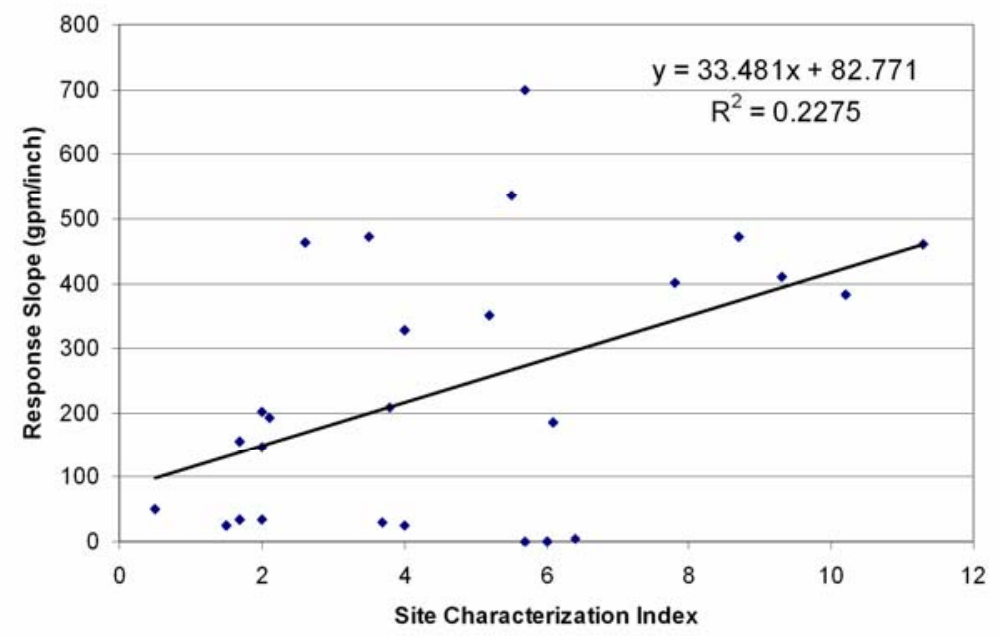

Figure 21.4 Relationship of response volume to site characteristics expressed as an index. 


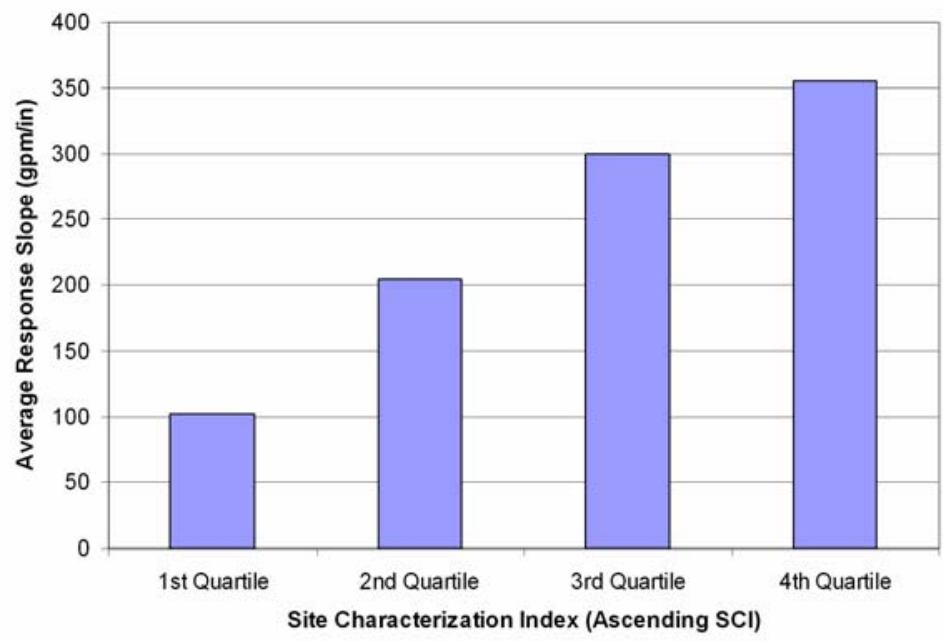

Figure 21.5 Average response volume by quartile sorted by increasing Site Characteristic Index (increasing $\mathrm{SCl}$ from left to right).

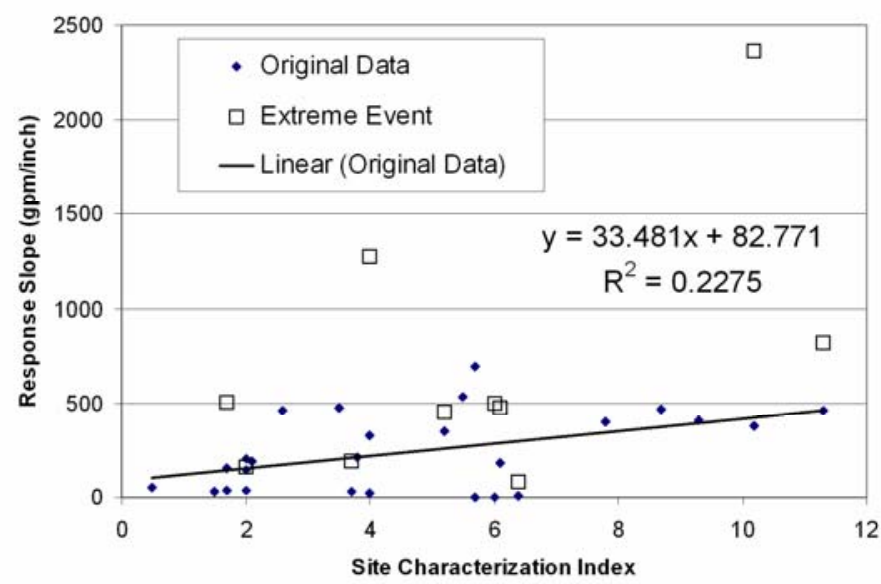

Figure 21.6 Relationship of response volume to site characteristics expressed as an index with independent extreme event overlain.

Figure 21.7 shows the response versus precipitation relationships for all monitor-events evaluated. Regression lines are forced through the origin and are presented for comparative purposes between seasonal data and are 
not intended to suggest any strength or weakness of the fit. Note that there are a large number of non-response events that cluster on the $\mathrm{x}$-axis making it difficult to see their influence on the regression line. To better understand the number of non-response events relative to the remaining analysis, Figure 21.8 illustrates the response volume distribution. Many of nonresponse event results are from locations that typically do not respond. It was noticed for the May 2004 event, not plotted, that many of the typically non-responding sites did respond under the more significant storm conditions (some of these are plotted in Figure 21.6). Due to variation between monitoring locations' duration, time period, and available data, the regression line in Figure 21.7 could be location-biased by some monitors having more events analyzed than others. The average of the individual monitoring location regression analyses is $232 \mathrm{gal} / \mathrm{in}(34.6 \mathrm{~L} / \mathrm{mm})$, thus giving equal weight to each location rather than equal weight to each monitor-event-response evaluated. The regression in Figure 21.7 did produce very similar results of $234 \mathrm{gal} / \mathrm{in}(34.9 \mathrm{~L} / \mathrm{mm})$.

Peak flow versus precipitation is shown in Figure 21.9. Similar to Figure 21.7, there are numerous non-response events that yield both zero volume and zero peak flow. Seasonal analysis was included in Figures 21.6 and 21.8. Two seasons were defined as (i) Dormant season as November through May and (ii) Growing season as June through October. It is recognized that Dormant and Growing seasons are not fixed from year to year as defined by the periods used for this analysis. The months selected above are based on the DWF analysis in which monthly averages over the two year period show a distinct reduction in baseflow during June through October. A more rigorous analysis might attempt to identify specific dates, or a narrow range of dates, when responses actually decline for each of the two monitoring years.

Figure 21.7 illustrates a pronounced seasonal difference in response volume. Whereas, Figure 21.9 indicates that peak flow is nearly independent of season. These findings are significant in that they support the conceptual development of the citywide model's hydrologic representation regarding footing drains using the RDII parameters.

Although DWF analysis is beyond the scope of this chapter, to summarize in terms of the FD monitoring work: the base FD flow was determined to be 0.019 and $0.004 \mathrm{gal} / \mathrm{min} / \mathrm{FD}$ equivalent $(\mathrm{gpm} / \mathrm{FD}$ equivalent) $(0.072$ and $0.015 \mathrm{~L} / \mathrm{min})$ for Dormant and Growing seasons, respectively (using the definition of seasons mentioned previously). 


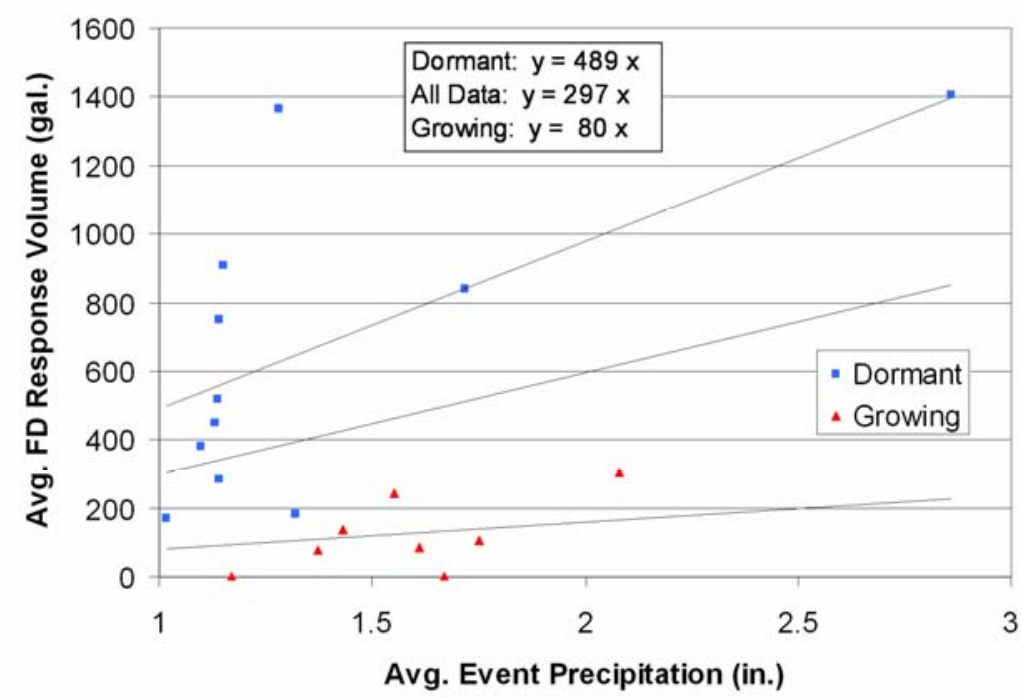

Figure 21.7 FD volume of response to precipitation for all monitors.

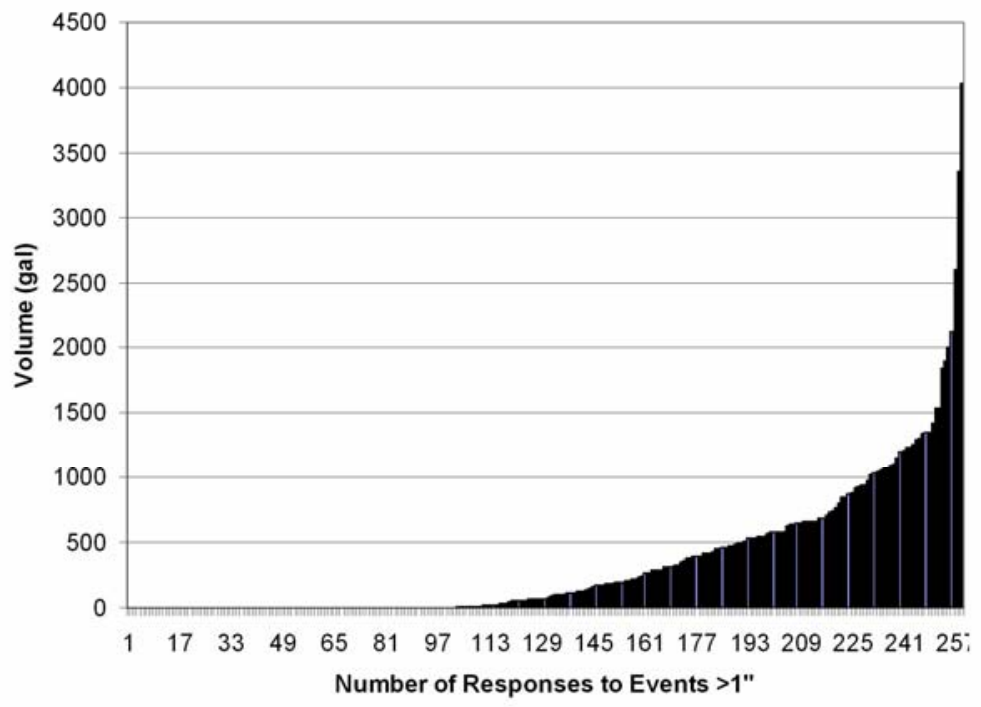

Figure 21.8 FD response volume distribution for all monitors. 


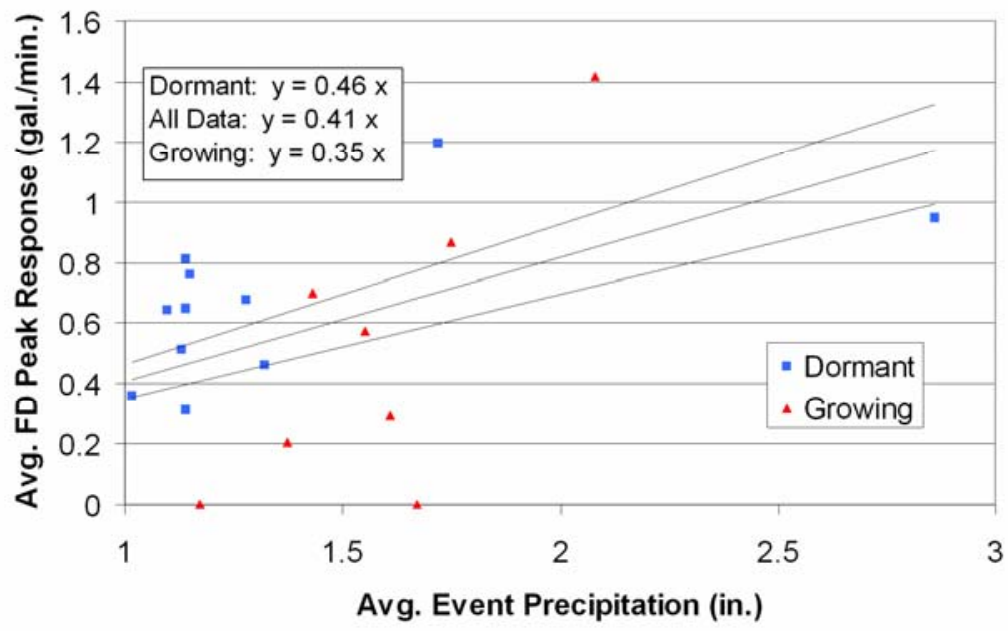

Figure 21.9 FD peak flow of response to precipitation for all monitors.

\subsection{Hydrology}

The apportioning of volume between the two component hydrographs, $\mathrm{C} 1: \mathrm{C} 3$, can be considered a shape parameter that is set at the sub-basin level. However, a broader grouping is made of this split for areas having similar characteristics. For each sub-basin, characteristics are assembled such as sewer billing data, footing drain equivalents, area, and working identifiers for groupings such as service district, meter tributary, incremental meter tributary, related rainfall source ID, average year of construction, and inflow node. The remaining shape $\mathrm{T}$ and $\mathrm{K}$ parameters that define the time to peak and the time to recession of each component hydrograph along with the initial abstraction, Vo, are set for sub-basin groupings.

The RDII allocation from the 40 flow meters to the 2,670 sub-basins begins with the total R determined through RDII analysis of flow monitoring data for Dormant and Growth conditions. Each sub-basin is allocated a share of the total response volume from the incremental RDII area it is associated with. Within each sub-basin, the RDII volume is further allocated as originating from both non-footing drain sources (representing paths such 
leaky joints, system cracks, illicit connection, etc.) and connected footing drains for sub-basins having them. The first step of the allocation is for each sub-basin to be assigned a minimum response attributable to the non-footing drain sources. This value varies from $1.2 \%$ for the Growth season to $2.0 \%$ for the Dormant season. These values were determined from baselines established on a response versus percentage of footing drain plots of all project-metering areas. The plots for the each season are shown in Figures 21.10 and 21.11 . The horizontal baselines at $2 \%$ and $1.2 \%$ represent the minimum RDII expected from non-footing drain sources for the Dormant and Growth seasons respectively.

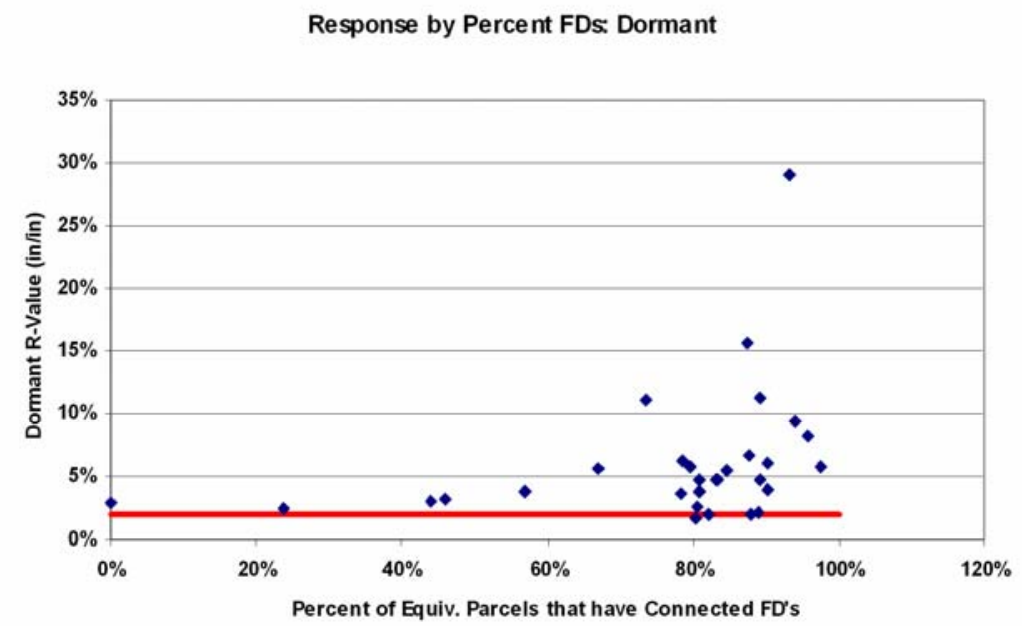

Figure 21.10 Minimum RDIl allocation to non-footing drain sources Dormant season.

The second allocation step is that any remaining RDII volume in excess of $1.2 \%$ and $2.0 \%$ for Growth and Dormant seasons respectively, are allocated to footing drains. However, this footing drain response is limited to $300 \mathrm{ft}^{3} /$ in of rainfall per footing drain equivalent $\left(0.3 \mathrm{~m}^{3} / \mathrm{mm} /\right.$ footing drain equivalent). This limit was selected from the knee-of-the-curve of 268 footing drain monitoring points and is the point below which $94 \%$ of all data fall. In cases where the maximum footing drain response plus the minimum non-footing drain response is exceeded by the total meter-determined volume, the remainder of that volume is added to the non-footing drain sources. In some cases some metered areas were restricted to an upper limit 
as low as $80 \mathrm{ft}^{3} /$ in of rainfall per footing drain equivalent $\left(0.09 \mathrm{~m}^{3} / \mathrm{mm} /\right.$ footing drain equivalent). This additional restriction was iteratively determined based on a somewhat arbitrary limitation of $30 \%$ response volume by any individual sub-basin. Some metered areas resulted in high responses from FD sub-basins that may not have been realistic. Therefore, to avoid the inclusion of extreme values where metering information was lacking, this restraint was imposed. In cases where this was applied, flows were rebalanced by shifting to non-footing drain sources within the metered area.

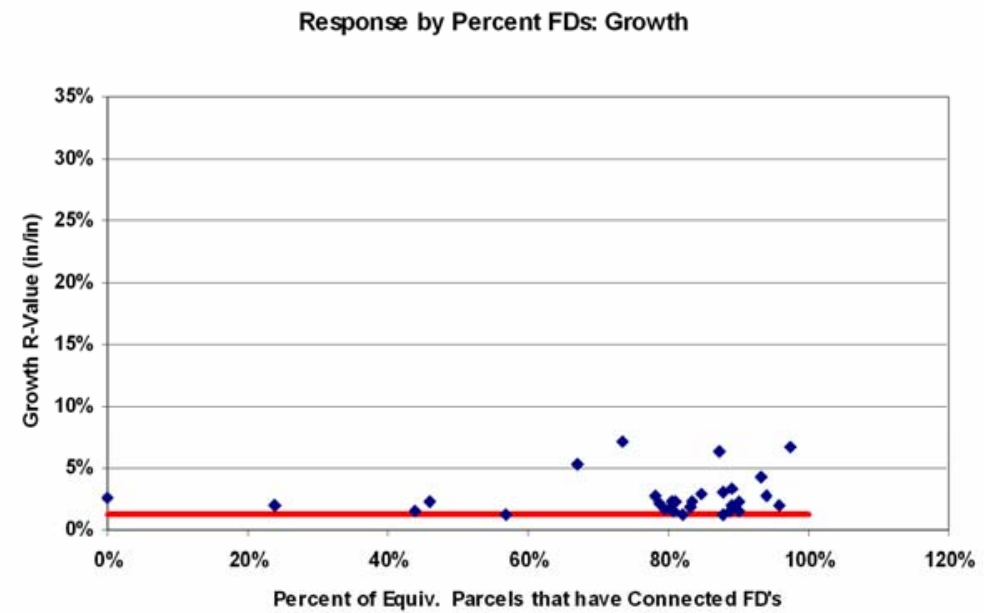

Figure 21.11 Minimum RDIl allocation to non-footing drain sources Growing season.

Splitting of volume to the component hydrographs is done as part of calibration. Once the Dormant season splits are determined, the Growth season parameters are determined by first assigning Growth season volume to the inflow hydrograph up to a maximum volume of that used for Dormant season inflow, with the remainder being assigned to the infiltration component hydrograph. If the Growth season's total response is less than that of the Dormant inflow volume, the entire Growth season response is assigned to the inflow component hydrograph. This approach is supported by Figures 21.6 and 21.8 in that Growing season does show less volume than that of Dormant; however, the peak inflow shows less variation between seasons. Therefore, the volume split was established assuming that 
the reduced volume from Dormant to Growing would first be removed from the infiltration component hydrograph and then the inflow hydrograph if necessary.

Again, only two component hydrographs were used, the first and third, one for inflow and one for infiltration; although Figure 21.1 illustrates that there are three that are available in SWMM. One parameter not shown on, but implied by, the figure is the split of volume between the hydrographs. This split distributes volume and thus affects the shape.

Individual shape parameters are required for each rain gage due to SWMM input configuration requirements. There are 123 rainfall input sets for the model based on $1 \mathrm{~km}$ x $1 \mathrm{~km}$ radar precipitation data "pixels" coupled with the individual incremental metering areas that require the flexibility of providing unique shape parameters. Furthermore, most incremental meter areas have both footing drain and non-footing drain areas that also require the flexibility of having shape parameter input, and the result is a total of 384 grouping levels for shape parameters that are input to the model. While this is much less than the 2,670 sub-basins that comprise these groupings, it remains a high level of detail. The 384 records input as EXTRAN F4 cards are derived from a broader grouping level defined in a parameter allocation spreadsheet. This more broadly defined level is based on similar response characteristics and is comprised of only six groups that may be dependent on the event simulated. These six groupings are distinguished as follows:

- $100 \%$ connected footing drains (1 set of shape parameters)

- $0 \%$ connected footing drains (1 set of shape parameters)

- Atypically large sub-basin sizes serving two of the suburban communities (typical-sized sub-basins are from 10 to 15 parcels; two sets of shape parameters)

- Mixed footing drain percentages with standard subbasin sizing (two sets of shape parameters)

\subsection{Conclusions}

The development of a screening tool, the SCI, shows promise regarding prioritizing future FDD effort and for potentially refining or verifying the adequacy of the citywide model's RDII. It is recommended that the criteria 
used to characterize the sites be made more objective to allow broader application e.g., allowing different personnel to produce similar results, or more fully utilizing GIS for characterization, particularly the relative elevation term. Further monitoring should be performed to confirm that response/SCI relationship holds in areas not prone to basement flooding as was the case for the monitoring analyzed for this chapter. A simple tool such as this can support FDD prioritization and could be used to refine the model's RDII allocation.

Seasonal variability is observed in both the wet weather volume and the DWF. However, the peak flow exhibited only a marginal seasonal variation. These findings support conceptual representation of RDII in citywide model regarding volume parameter seasonal variation and the allocation of FD response volume primarily to inflow rather than infiltration hydrographs. While the methods used to allocate wet weather response to the citywide model appear reasonable, further refinement could be made regarding the arbitrary limit of $30 \%$ to the individual sub-basins as some of the sub-basins affected could be investigated through use of footing drain flow monitoring to better assess actual contribution there.

\section{References}

Sanitary Sewer Overflow Study Task Force, Report to City of Ann Arbor City Council, http://www.cdm-mich.com/aa-sso/FinalReport.htm, SSO Prevention Study - Final Report, June 2001.

Schultz N.U.,Wood D.M., Adderly V., and Bennett D., 2001. RDI/I Quantifcation Research Results, Conference Proceedings of the $4^{\text {th }}$ DHI Software Conference \& DHI Software Courses, Helsingør, Denmark, 6-8 June 2001.

Sherman, B. J., C. Rolfe, P. P. Perala, C. Hupy, M. J. TenBroek, "Implementing SSO Control - Technical Aspects", Proceedings of the Water Environment Federation WEFTEC 2002 Conference. Chicago, IL. October 2002.

Stonehouse, M.C., B.J. Sherman, P.P. Perala, D. Wilburn, M.J. TenBroek and H. Fan. 2005. "Modeling Every Sanitary Pipe in the City: Unique Aspects and Benefits." Journal of Water Management Modeling R225-04. doi: 10.14796/JWMM.R225-04.

Zawacki, J. R., I. Kotlyar, B. J. Sherman, M. J. TenBroek, "Effective I/I Removal with Footing Drain Disconnection as a Solution for SSO and Basement Flooding", Alternate Paper, 2005 WEF Collection Systems Conference - Sustaining Aging Infrastructure: System, Workforce, and Funding. Boston, MA. July 17-20, 2005. 